\title{
MARIÁTEGUI E O SOCIALISMO INDO-AMERICANO
}

Marília Gabriella Machado²

\section{Resumo}

José Carlos Mariátegui é considerado um dos grandes pensadores marxistas do século XX e possui rica obra sobre a realidade peruana e o socialismo. Este trabalho tem como objetivo principal compreender o projeto de socialismo para Mariátegui, a partir da análise sobre a Revolução Bolchevique, sobre a formação social peruana e sobre o debate acerca da influência de Sorel na construção de seu projeto revolucionário.

Palavras-chave: Mariátegui; Peru; Socialismo.

\section{MARIÁTEGUI Y EL SOCIALISMO INDO-AMERICANO}

\section{Resumen}

José Carlos Mariátegui es considerado uno de los grandes pensadores marxistas del siglo XX y tiene una rica labor sobre la realidad peruana y el socialismo. Este artículo tiene como objetivo principal entender el proyecto de socialismo para Mariátegui, desde el análisis sobre la Revolución Bolchevique, sobre la formación social peruana y sobre el debate sobre la influencia de Sorel en la construcción de su proyecto revolucionario.

Palabra-chave: Mariátegui; Perú; Socialismo.

\section{MARIÁTEGUI AND INDIAN AMERICAN SOCIALISM}

\section{Abstract}

José Carlos Mariátegui is considered one of the biggest marxist's thinkers from XX century and has a rich work about peruvian reality and socialism. This job has the main objective understand Mariátegui socialism's project, from Bolshevik Revolution analyses, about the social and discussion construction of peruvian and about discussion of Sorel influences in the construction of your revolutionary project.

Key words: Mariátegui; Peru; Socialism.

\footnotetext{
${ }^{1}$ Artigo recebido em 16/06/2019. Primeira avaliação em 22/09/2019. Segunda avaliação em 03/09/2019. Aprovado em 15/12/2019. Publicado em 22/05/2020. DOI: https://doi.org/10.22409/tn.v18i36.29059

${ }^{2}$ Mestranda em Ciências SociaiS da Universidade estadual de São Paulo (UNESP-Marília) - Brasil, bolsista CAPES. Email: gabriella.borgesmachado@hotmail.com. ORCID: 0000-0003-1690-9983
} 


\section{Introdução}

Em meio aos conflitos da Primeira Guerra Mundial e a partir de 1917, o proletariado e o campesinato russo desenvolveram um processo de transformação da estrutura estatal burguesa que se iniciara em torno de 1905 na Rússia. Essa transformação teve caráter popular e democrático no sentido de desenvolver um projeto de Estado socialista para a democratização da cultura, da educação e do trabalho centrado na atividade humana enquanto atividade sócio-metabólica. $A$ Revolução de Outubro foi decisiva para a humanidade e produziu o maior movimento operário organizado de toda a história moderna, "tornou-se, portanto, tão fundamental para a história deste século quanto a Revolução Francesa de 1789 para o século XIX.”. (HOBSBAWM, 1995, p. 62). Nesse sentido, o programa da Revolução Bolchevique teve o objetivo de proclamar e organizar um sistema alternativo internacional que superasse o capitalismo.

José Carlos Mariátegui (1894-1930) foi muito influenciado pela Revolução de 1917. Ao analisar a realidade de seu país esteve à frente das reflexões sobre o socialismo peruano como uma das maiores referências ao analisarmos o socialismo latino-americano do século $X X$, além de importante contribuição para a teoria do socialismo. O intelectual e militante fundou em 1928 o Partido Comunista Peruano com o nome de Partido Socialista Peruano - recebeu a denominação de Comunista apenas em 1930, momento do qual aderiu completamente a Internacional Comunista.

Foi capaz de reunir em seus textos a questão política e econômica, a arte e a cultura, o jornalismo e a ação práxis revolucionária. De tal maneira, seu projeto de socialismo buscou levar ao Peu à modernidade revolucionária do século $\mathrm{XX}$, já que em sua época a onda revolucionária chegava aos demais países e se tornava ordem do dia para a classe operária internacional.

\section{Revolução Bolchevique}

A Rússia do século XIX era um país que não havia desenvolvido por completo suas forças produtivas e a indústria, além de absolutista feudal, composto em sua maioria pelo campesinato e por diversos povos que habitavam o território. Em primeiro 
momento, nota-se que a industrialização e o desenvolvimento do capitalismo na Rússia ocorreram por indução do Estado feudal-absolutista, o mesmo criou vagarosamente um proletariado e uma burguesia nova/industrial. Mesmo em um país atrasado, as forças produtivas, de modo dialético, se desenvolviam, aumentavam e acirravam a luta de classes, portanto, abria-se espaço para um processo revolucionário de cunho popular.

A Rússia buscou tentativas de expansão e conquista do comércio marítimo internacional. Uma dessas tentativas foi a Guerra da Criméia (1853-1856), que colaboraria para a conquista do Mar Quente, consequentemente, conquistaria a Turquia e o Mar Mediterrâneo. Com a derrota da guerra, a Rússia iniciou um processo de industrialização com o objetivo de construir estradas de ferro. Nesse período nasce junto à burguesia industrial, a sua força antagônica: o proletariado.

Lenin, por meio da dialética de $\mathrm{Marx}^{3}$, analisa a possibilidade de o capitalismo se desenvolver na Rússia por meio das relações de mercado que adentravam o campo e também com a dissolução das relações sociais feudais. Compreendia que a estratégia necessária deveria ser a derrubada do Estado feudal-absolutista, de modo que a conquista da emancipação política seria inevitável.

Lancemos de antemão à questão: A Revolução Russa foi filha da Primeira Guerra Mundial? A guerra imperialista colocou a revolução na ordem do dia como um dos acontecimentos mais importantes do século $X X$, pois foi o momento da massa proletária se unir e resistir ao capitalismo e provar que era possível a superação da velha ordem e do velho mundo. Contra a guerra, o proletariado se uniria e demonstraria sua capacidade de organização prática e política ao conquistar o espaço para a revolução internacional socialista.

Lenin tem posicionamento contrário à guerra imperialista e compreende que o momento seria eficaz com a saída da guerra e o início de uma guerra civil revolucionária internacional contra a burguesia e os capitalistas, pois a guerra imperialista nada interessava ao trabalhador. Portanto, há a necessidade de construção de novos instrumentos políticos de luta revolucionária que possibilitassem a organização proletária, o que permitiria que a revolução eclodisse em qualquer país

\footnotetext{
${ }^{3}$ Marx no final de sua vida enxergava na Rússia um espaço para o desenvolvimento de uma revolução socialista que se espalhasse pela Europa.
} 
que estivesse na guerra ${ }^{4}$.

Em 1914 a Internacional Socialista entrou em colapso devido a guerra de caráter imperialista. Em meados da segunda quinzena de maio e da primeira metade de junho de 1915, Lenin escreve La Bancarrota de la II Internaciona ${ }^{5}$ e desenvolve as concepções sobre oportunismo e social-chovinismo, além de táticas para a luta contra essas correntes atuantes. Lenin sintetiza que

La aceptacion de la ideia de la defesa de la pátria em la presente guerra imperialista, la justificación de la alianza de los socialistas com la burguesia y com los gobiernos de "sus" países em esta guerra, la renuncia a propugnar y apoyar las acciones revolucionarias del proletariado contra "su" burguesia, etc. (LENIN, 1976, p.256).

A força dos oportunistas provém necessariamente da aliança com a burguesia, com os governos e com os estados maiores. O oportunismo é um produto social de toda uma época histórica. A bancarrota da II Internacional se manifesta na maioria dos partidos social-democratas oficiais da Europa e demonstra o triunfo do oportunismo devido à transformação de partidos social-democratas em partidos operários nacional-liberais. Nas condições de guerra o oportunismo engendrou o social-chovinismo, ambos se incubaram no período de desenvolvimento do capitalismo, fez com que os trabalhadores se sentissem aburguesados, com colaboração com a classe antagônica, de modo a se tornar uma massa amorfa, sem enxergar como saída à revolução socialista.

Portanto, o que Lenin procura demonstrar é que a II Internacional estava em falência devido ao fato de o oportunismo existir dentro da organização e ser um "abscesso" burguês nos partidos socialistas.

Saltaremos para 1917, precisamente em março, quando as grandes greves de massa de São Petersburgo colocou abaixo a monarquia absolutista e emergiu a revolução socialista internacional que seria derrotada em 1921. A revolução que era esperada na Alemanha, no entanto, ocorreu na Rússia - um país com forças produtivas menos desenvolvidas, mas que devido à situação de fome e miséria do proletariado e, principalmente, do campesinato fizeram com que a luta de classes se tornasse mais acirrada e desenvolvesse um proletariado mais consciente e combativo.

\footnotetext{
${ }^{4}$ Veremos adiante o posicionamento do PSI na guerra e no que influenciou as mudanças da Itália e o nascimento de uma Itália fascista.

${ }^{5}$ Em 1910 Lenin rompe sua influência com Kautsky e faz uma leitura, já um tanto tardia, de Hegel. No texto em questão é notável o rompimento com o teórico alemão.
} 
Na revolução de 1905, instaurou-se a possibilidade da criação de um Estado operário organizado pelos sovietes, mas, dessa vez, em 1917, por conta da situação nacional e internacional, a Revolução Proletária foi colocada como tarefa imediata.

Lenin retorna à Rússia em abril e apresenta um documento que reorienta o partido bolchevique. As Teses de Abril tem como composição uma espécie de projeto de plataforma do partido proletário com a proposta de se tornar um partido comunista, com a palavra de ordem "Todo poder aos sovietes!". Em junho é realizado um congresso dos sovietes que reafirmam a maioria de mencheviques e SR. A proposta dos bolcheviques foi de ocupar as ruas e trabalhar uma ofensiva contra o governo provisório que reprimiu intensamente.

Entretanto, há uma crise nessa dualidade de poder porque os liberais eram favoráveis à desarticulação dos sovietes e passam para 0 processo contrarrevolucionário - o que não ocorre devido à resistência dos operários -. Os conselhos operários que surgiram em 1905 voltaram como embrião desse novo Estado Operário que tinha como tarefa se contrapor ao Estado burguês. Essa dualidade de poderes fez com que surgisse a possibilidade de exterminar todo o poder da nobreza feudal e da burguesia, com a finalidade de instaurar a ditadura democrática do proletariado e do campesinato no momento em que os bolcheviques atraíssem os sovietes que deveriam conquistar o poder e exercer a hegemonia operária, com o objetivo de construção de um Estado Socialista.

Nessas condições, a instauração da ditadura democrática do proletariado na Rússia representaria apenas um momento de aproximação da revolução socialista internacional, cujo território compreendia toda a área atingida pela guerra imperialista. (DEL ROIO, 2007, p. 71).

É possível notar que uma das consequências da Guerra para a classe trabalhadora foi colocar o proletariado em combate direto com os operários de outros países. Já a Revolução Bolchevique agiu diretamente na consciência política e cultural, a fim de estabelecer uma luta pela hegemonia das classes subalternas em torno do partido revolucionário para a conquista de um novo Estado. A Rússia tornouse palco revolucionário e de consolidação do poder bolchevique ao colocar a revolução na ordem do dia e inspirou outros países e o proletariado internacional a se organizarem pela construção de uma nova sociedade, longe das amarras da exploração e da servidão capitalista. Mesmo com os destroços causados pela guerra, 
as classes subalternas russas foram capazes de conceber um novo ser social, um novo homem, uma nova mulher, uma nova sociedade que mudou a história da humanidade, pois

A revolução russa é o domínio da liberdade: a organização se constitui por espontaneidade, não pelo arbítrio de um "herói" que se impõe através da violência. Trata-se de uma elevação humana contínua e sistemática, que segue uma hierarquia, a qual, em cada situação concreta, cria os organismos necessários da nova ordem social. (GRAMSCI, 2004, p.209).

Gramsci (1891-1937) interpreta o socialismo como um contínuo devir histórico exercido por meio do controle do proletariado, onde a socialização é intensificada e aperfeiçoada com o passar do desenvolvimento do novo Estado. O socialismo é organização política e econômica, saber e vontade, obtidos com a atividade cultural. O socialismo, segundo Gramsci, é "um desenvolvimento infinito em regime de liberdade organizada e controlada pela maioria dos cidadãos, ou seja, pelo proletariado.". (GRAMSCI, 2004, p. 209).

Dessa forma, o princípio da teoria socialista é o da luta de classes, para tanto, o proletariado se tornou um sinônimo de opressão por parte da burguesia. Isso não difere de um país para o outro, ao contrário. A sociedade capitalista é dividida em classes sociais: a burguesia e o proletariado, além do campesinato e outros grupos sociais existentes. Nesse caso, Mariátegui compreende que a emancipação dos trabalhadores deve ser obra dos próprios trabalhadores e

No final de 1917, com 23 anos de idade, Mariátegui ficaria sabendo da Revolução de Outubro, na Rússia. Como ocorreu com muitos outros, aquele evento iria exercer uma profunda influência no jornalista. (PERICÁS, 2012, p.19).

As informações que chegavam à América Latina eram noticiadas e filtradas por agências estrangeiras. O acontecimento revolucionário na Rússia foi considerado uma mudança progressista que criava um governo moderno e democrático. Devido a falta de informação, será apenas com a Revolução de Outubro e com a instauração dos bolcheviques no poder que a imagem da Rússia socialista ficou mais clara para os outros países, por mais que houvessem sérias distorções de informações por parte dos inimigos sobre a escassez de comida e a guerra civil. (PERICÁS, 2012, p.19).

No caso italiano, embriões de uma revolução socialista podem ser evidenciados durante os anos de 1919-1920, tendo como apogeu a ocupação das fábricas na cidade de Turim. A organização dos soviets pôde ser vista nessa cidade com objetivo 
semelhante ao russo: ser o embrião do Estado operário, organismo do proletariado que consolida dialeticamente a cultura, o princípio educativo, a autoeducação, a autogestão e o autocontrole do que se produz pelo operário qualificado. Nesse cenário, Gramsci "participou ativamente da tentativa revolucionária turinense e elaborou debates no periódico L'Ordine Nuovo sobre a relação dos Conselhos com o Sindicato e com o Partido Socialista.". Devido às particularidades italianas, de oposição do Partido Socialista Italiano e dos Sindicatos no desenvolvimento e expansão dos Conselhos de Fábrica,

o proletariado organizado nos conselhos de 1919-1920 demonstraram a capacidade e o poder da classe trabalhadora para a elaboração de uma nova forma social, política e econômica. (MACHADO, 2019, p.12).

No caso latino, as condições também eram diversas. Para tanto, é preciso compreender a dialética do trabalhador latino-americano que ficava parte do tempo como rural, camponês e mineiro e não como uma vanguarda sustentada na fábrica, como em Turim, é de grande importância para compreender o pensamento social e político latino-americano e a obra de Mariátegui.

Portanto, a obra de Mariátegui é de grande importância para pensarmos na América Latina e no desenvolver do marxismo enquanto teoria e práxis, mas em diferentes condições da Rússia e da Europa. A ideia central é de que o marxismo é uma nova concepção de mundo que difere e que se supera das outras ciências, e, por se tratar de teoria e prática, pode ser traduzida nas distintas formações sociais. Para isto, devemos entender a realidade do Peru e a relação entre campo e cidade, pois organizar uma vanguarda peruana deveria significar o mesmo que, segundo Mariátegui, organizar uma vanguarda urbana e campesina.

\section{O desenvolvimento do capitalismo no Peru}

É no período da juventude que Mariátegui começa a se interessar pelos assuntos políticos e inicia seu trabalho na redação do jornal Círculo de Propaganda Socialista, tornando-se o mais novo periodista de Lima. O jornal discutia as greves e o movimento operário, além de apoiar as lutas do movimento estudantil peruano.

A relação de Mariátegui com o Peru é um tanto diversa da relação dos grandes expoentes das ideias socialistas na Europa. Contrário às Teses do Comintern, o autor 
foi considerado um marxista heterodoxo e um revisionista do marxismo durante o século XX. A heterodoxia de Marátegui contribui justamente para pensarmos a relação e a construção do socialismo na América Latina, além de questionarmos sobre como desenvolver as condições revolucionárias em uma região da qual não há um proletariado organizado ou uma vanguarda.

A questão fundamental é compreender o leninismo de Mariátegui, pois tem um diferencial importante quando levamos em consideração as condições singulares do Peru. A tática leniniana de conquistar os camponeses para o Partido operário não funcionaria na estrutura peruana, pois o país deveria ser considerado em sua complexidade demográfica, assim como na pequena quantidade de proletários.

No Peru, sobravam aos camponeses as piores terras. Devido à dominação imperialista norte-americana - exportação de capitais financeiros para países subordinados -, foi iniciado um processo de subordinação dos senhores feudais e o inicio de um capitalismo. Diferente do feudalismo russo, no Peru havia um feudalismo que colaborava de maneira funcional para a instauração de capitais financeiros. De certa forma, para a transição capitalista, o país foi capaz de desenvolver o nexo do movimento camponês com o urbano, de maneira que fundamentava e explicitava a necessidade de compreensão da questão nacional que se iniciava com a questão do Império Inka.

O Império dos Inkas foi o mais importante para a economia peruana já que estes utilizavam e valorizavam o território do Império com a construção de canais e caminhos para a troca de mercadorias. $O$ trabalho coletivo e o esforço comum se tornavam sociais. Mas, devido a colonização espanhola, a sociedade Inka foi destruída e o processo de colonização teve como objetivo uma nova política e economia para a Colônia, sendo a de uma estrutura de empresa militar e eclesiástica, fazendo com que o capitalismo peruano se desenvolvesse sob pressão do imperialismo. (MARIÁTEGUI, 1975, p.13).

Segundo o autor, a importação de escravos negros para o Peru fez brotar elementos de uma sociedade feudal que estava ainda conectada com as características de uma sociedade escravista, mas que tinha como objetivo principal a exportação de ouro e de prata para o interesse comercial do Ocidente capitalista. Com a exploração de guano e de salitre iniciou um ativo tráfico com o mundo ocidental, o que colocou o país no controle do capital britânico, consolidando no Peru uma 
sociedade diversa, com traços escravistas, feudais e aristocráticos, ou seja, os primeiros elementos do capital comercial e bancário de uma economia costeira. Formava-se no Peru uma burguesia - sucessores da Colônia -- que se confundia com a aristocracia, mas também um novo proletariado combativo e antagônico à lógica do Capital. Ainda assim, o capital financeiro interno estava subordinado aos interesses do capital estrangeiro. (MARIÁTEGUI, 1975, p.21).

Por conta da aparição de uma indústria moderna, com fábricas, transportes e usinas, a função do capital financeiro esteve relacionada com o surgimento de bancos nacionais que financiavam diversas empresas industriais e comerciais e que demonstravam o interesse do capital estrangeiro e da propriedade agrária. Com a abertura do Canal do Panamá (1914), o Peru começou a fazer parte da civilização ocidental e criou um tipo de aristocracia feudal. Mesmo mantendo o caráter de país agrário e o cultivo de terras ocupando a maior parte da população nacional, a sobrevivência costeira era traduzida pela pobreza da vida urbana. As cidades eram formadas para auxiliar a produção nacional e as indústrias e os comércios estavam sujeitos aos regulamentos e ao controle capitalista.

Segundo Mariátegui (1975, p.34), a concentração capitalista foi precedida por uma etapa de livre concorrência feudal, sendo o capitalismo um fenômeno urbano com o espírito de um burgo industrial, manufatureiro e mercantil. Notamos que a colonização extrativista e a consolidação de uma burguesia agrária-financeira somado à uma estrutura militar-eclesiástica é associada à ideologia protestante e católica junto ao desenvolvimento das práticas capitalistas europeias. Dessa forma, é possível compreender uma ética no desenvolvimento do capitalismo nas Colônias e nos países subordinados ao Ocidente. Em sua obra, Mariátegui compreende a totalidade do Imperialismo e também o desenvolvimento das forças produtivas na conquista pelos países periféricos.

Com o desenvolvimento do capitalismo e a chegada de um novo proletariado, vários problemas devem ser solucionados. Mariátegui se coloca ao lado de uma concepção revolucionária, antideterminista e antipositivista e é possível vislumbrar grande influência de Georges Sorel (1847-1922) em sua obra e na construção de seu projeto de socialismo. É possível notar a capacidade de inovação de Mariátegui ao traduzir o leninismo para a realidade peruana; um dos principais pontos foi compreensão da importância dos trabalhadores indígenas no processo revolucionário, 
compreendendo-os como sujeitos revolucionários que deveriam escrever sua própria história.

\title{
3. Mariátegui e a importância do mito
}

Como dito, uma das referências de Mariátegui foi Georges Sorel, o intelectual francês que realizou inúmeras críticas ao positivismo e ao cientificismo, influência que pode ser notada tanto em Mariátegui quanto em Gramsci. ${ }^{6}$ O pensador latino refuta o que considera ser o cientificismo mencionado e reivindicado por Marx e Engels e fundamenta sua questão no voluntarismo e na ação política como táticas revolucionárias. (Galastri, 2015, p.97). Portanto, as questões do mito e da greve geral surgem justamente como um oásis da revolução que

\begin{abstract}
aposta no movimento espontâneo das massas trabalhadoras, motivada não por uma vanguarda que tivesse analisado "cientificamente" as condições objetivas e subjetivas para a sublevação, mas pela paixão nutrida pela imagem messiânica do mito. (GALATRI, 2015, p.97).
\end{abstract}

Para Sorel, não seria possível lançar de vez todos os trabalhadores a uma greve geral, pois uma revolução não seria resolvida apenas em uma batalha. Dessa forma, notamos a importância dos mitos como "medios de obrar sobre el pesente, y por lo tanto, cualquier discussión que se relacione con el modo de aplicarlos materialmente al curso de la historia carece de sentido." (SOREL, 1992, p.127). O que interessa é o conjunto do mito que pode se desenvolver em um processo revolucionário com conflitos necessários para o triunfo do proletariado.

No texto escrito por Mariátegui, publicado em 16 de janeiro de 1925 e republicado na revista Amauta $^{7}$ em junho de 1930, podemos observar a influência de Sorel quando o jornalista peruano compreende as questões do mito relacionado com alguns problemas da burguesia. Segundo o autor, um dos grandes problemas é a falta

\footnotetext{
${ }^{6}$ A influência de Sorel na obra gramsciana pode ser observada nas diferentes fases de seus escritos: durante o período pré-carcerário (1911-1926), principalmente com as noções de antijacobinismo, críticas aos intelectuais, ao Partido e ao Sindicato, além de certo entusiasmo com a experiência conselhista (1919-1920) até seus anos no cárcere (1926-1937), com as noções críticas do mito da greve geral, seu posicionamento mais favorável ao jaconinismo e compreensão diversa dos intelectuais e da função do Partido.

${ }^{7}$ A Revista Amauta teve como objetivo principal expressar a solidariedade da vanguarda peruana por seu esforço em organizar a central do proletariado.
} 
de um mito, de uma fé e de uma esperança, pois a humanidade sente falta de algo que vá além da razão, já que nem mesmo a razão a ou a ciência podem realizar o papel do mito político. (MARIÁTEGUI, 1970, p.18).

Os mitos das revoluções burguesas: a liberdade, a democracia e a paz foram quebrados com a Guerra Imperialista (1914-1918) e as ideias iluministas caíram por terra, no entanto, o autor nota que foram importantes para o fim do feudalismo e das monarquias da Europa central, da Rússia e da Turquia, provando mais uma vez o valor do mito.

Pero el hombre, como la filosofia lo define, es un animal metafísico. No se vive fecundamente sin una concepción metafísica de la vida. El mito mueve al hombre en la historia. Sin un mito la existencia del hombre no tiene ningúm sentido histórico. La historia la hacen los hombres poseídos e iluminados por una creencia superior, por una espezanda super-humana; los demás hombres son el coro anônimo del drama. (MARIÁTEGUI, 1970, p.19).

Mariátegui afirma que $\mathrm{o}$ homem sente a necessidade de um mito, e o proletariado possui um mito: o mito da revolução social, um mito que se move com fé e ativamente. Portanto, o mito possui uma força para o proletariado, a força dos revolucionários que não está na ciência, mas na sua ação política direcionada e organizada para determinado fim. Notamos que Mariátegui enxerga em Sorel a incitação de uma ação, além da grande contribuição contra o reformismo e o positivismo. Podemos entender que o jornalista peruano se agarra às ideias de Sorel como uma fuga para os problemas do determinismo marxista, de fato, observamos que existe nos textos do autor a questão do mito e de uma fé revolucionárias que se descompromete do positivismo incrustrado nos Partidos Socialistas e na Internacional. O ponto mais importante é que devido a influência soreliana, há uma maneira de impelir os homens à ação que escapa da mobilidade positivista e apenas o mito teria a capacidade de preencher o vazio do homem moderno, já que o capitalismo tem como uma de várias consequências, o desencantamento do homem. Em outras palavras, o mito age no imaginário da ação política e revolucionária que é construído no coletivo; é a representação de imagens que impulsionam as causas humanas, sendo o motor do movimento revolucionário.

Michael Lowy (2005, p.02) realiza uma crítica ao dizer que a singularidade do marxismo proposto pelo jornalista e militante comunista está em núcleo irredutivelmente romântico. Segundo Lowy, após a morte de Marx e Engels surgem 
duas correntes opostas no marxismo, e é na segunda corrente, de um romantismo utópico revolucionário que Mariátegui se encontra fundamentando sua tese socialista diferente da proposta pela Internacional, em um contexto completamente diverso da Europa e da Inglaterra.

uma evolucionista e positivista, para qual o socialismo é apenas o coroamento e a continuação, numa economia coletivista e planificada, dos avanços conquistados pela civilização industrial burguesa moderna (Plekhanov e Kaustky e seus discípulos na Segunda e Terceira Internacionais); e uma outra, que se poderia designar como romântica, na medida em que critica as "ilusões do progresso" e sugere uma dialética utópico-revolucionária entre o passado précapitalista e o futuro socialista. São exemplos desta segunda corrente, na Inglaterra, desde Willian Morris até marxistas da segunda metade do século XX (E. P. Thompson, Raymond Wilians), e, na Alemanha autores como Ernest Bloch, Walter Benjamin e Hebert Marcuse). (LOWY, 2005, p.10).

No entanto, a crítica de Lowy está num aspecto cultural, pois notamos nos textos de Mariátegui a influência soreliana enquanto um cânone de ação e de interpretação, mas a base epistemológica é o pensamento leniniano.

Do ponto de vista da prática política, é o bolchevismo que constitui a força que traz uma "energia romântica" para a luta do proletariado. Sorelismo e bolchevismo lhe parecem próximos por seu espírito revolucionário, por sua recusa do reformismo parlamentar e por seu voluntarismo romântico. (LOWY, 2005, p.17).

Na realidade, Mariátegui realiza uma crítica à sociedade capitalista, não apenas por um meio cultural, mas em textos que tratam sobre o atiimperialismo e a necessidade de compreensão da singularidade peruana para a realização de uma transformação radical da sociedade, o fato é que Mariátegui não desvincula a questão cultural crítica com a formulação de uma nova sociedade. O anticapitalismo do peruano está relacionado com a quebra do domínio burocrático e com uma racionalidade pragmática que pode ser encontrada também em Max Weber.

Se trata, efetivamente, de la lucha final de uma época y de uma classe. El progresso -o el progresso humano- se cumple por etapas. Por consiguiente, la humanidad tiene perennemente la necesidad de sentirse próxima a una meta. La meta de hoy no será seguramente la meta de mañana; pero, para la teoria humana en marcha, es la meta final. (...) El proletariado revolucionario, por ende, vive la realidade de una lucha final. (MARIÁTEGUI, 1970, p.24). 
É importante compreender a necessidade da greve geral e dos movimentos espontâneos dos trabalhadores, pois a greve geral também é um mito, e a prática das greves têm como horizonte principal estabelecer uma greve geral e promover uma nova cultura que possua a necessidade da cisão dos ideais burgueses incrustados no proletariado. Ou seja, é necessária a separação entre as classes sociais, e, nutrir esse sentimento subjetivo é fundamental para realizar oposição à estratégia reformista. Mariátegui está alinhado às questões singulares de seu páis e compreende a necessidade de criação de valores próprios da classe operária e de destruição dos valores burgueses. Portanto, o mito pode fomentar a ação política revolucionária das massas.

\section{O socialismo no Peru e o problema indígena}

O problema indígena foi compreendido por Mariátegui (1975, p.35) dentro de sua realidade, a questão da terra. A crítica socialista foi capaz de observar e analisar a questão quando voltada à questão da propriedade de terras e do problema do latifundiário. A solução do problema está na resolução social e seus realizadores devem ser os próprios índios. O problema não poderia ser resolvido em uma reação da classe ou em uma forma humanitária e abstrata, mas com uma nova política agrária que solucione organicamente o problema. Para tanto, Mariátegui define algumas questões necessárias e pontuais que são importantes para compreender seu programa de socialismo. O ponto de partida é uma política agrária socialista de nacionalização da terra com práticas voltadas às condições concretas da economia do país. O Estado também deveria intervir nas transformações das comunidades agrícolas em cooperativas, além de controlar a exploração capitalista e o confisco de terras não cultivadas. Seria obrigação do Estado a organização da agricultura e a difusão na massa rural por meio da educação e das escolas rurais.

Para isto, a necessidade que os índios escrevessem sua própria história e reivindicasse o direito a terra, pois com a terra no poder e controle do capital ocorre uma expropriação da dimensão do trabalho. A importância do socialismo indoamericano está na conscientização e na inserção das massas indígenas para a assimilação das ideias revolucionárias. 
Na obra de Mariátegui é possível encontrar uma análise de conjuntura de seu tempo, como também uma preocupação em conhecer a história, de maneira a considerar as conjunturas nacionais e internacionais para o desenvolvimento revolucionário. A questão da violência soreliana se faz presente ao notarmos a perspectiva de um sindicalismo revolucionário para enfatizar a questão da luta de classes, servindo novamente o mito como uma mola propulsora para a ação política revolucionária. Existia a necessidade de consolidação de um sindicalismo revolucionário que não atenuasse as oposições, ao contrário, com a necessidade de destacá-las para dar um aspecto sólido.

Mariátegui afirma um projeto de Revolução Socialista fundamentado na construção de uma Revolução Peruana, para isto, escreve sua obra analisando as contradições peruanas e como o capitalismo se desenvolveu no país, de maneira que seu projeto abrange o vínculo da classe trabalhadora com o projeto socialista. $O$ socialismo está na organização da classe trabalhadora, na construção de uma nova hegemonia e de um Estado de novo tipo.

\begin{abstract}
El movimiento clasista, entre nosotros, es aún muy incipiente, muy limitado, para que pensemos en fraccionarle y escindirle. Antes de que llegue la hora, inevitable acaso, de una división, nos corresponde realizar mucha obra común, mucha labor solidaria. Tenemos que emprender juntos muchas largas jornadas. Nos toca, por ejemplo, suscitar en la mayoría del proletariado peruano, conciencia de clase y sentimiento de clase. Esta faena pertenece por igual a socialistas y sindicalistas, a comunistas y libertarios. Todos tenemos el deber de sembrar gérmenes de renovación y de difundir ideas clasistas. Todos tenemos el deber de alejar al proletariado de las asambleas amarillas y de las falsas "instituciones representativas". Todos tenemos el deber de luchar contra los ataques y las represiones reaccionarias. Todos tenemos el deber de defender la tribuna, la prensa y la organización proletaria. Todos tenemos el deber de sostener las reivindicaciones de la esclavizada y oprimida raza indígena. (MARIÁTEGUI, 1974, p.108).
\end{abstract}

Segundo o autor, a classe social que está mais avançada na organização comunista é a inca, pois há uma vocação coletivista e imparcial, uma relação complexa aos povos conquistados e assimilados pela guerra. $\mathrm{O}$ socialismo indoamericano é o que Mariátegui pretende construir no país, com a aliança de classes entre o proletariado urbano, o campesinato e os índios. Era possível se encontrar nas aldeias as práticas de cooperação e de solidariedade que, segundo o autor, eram a expressão de um espírito comunista.

A mais ousada e herética proposição de Mariátegui, aquela que provocará as maiores controvérsias, é a que resulta da passagem de 
suas análises históricas sobre o "comunismo inca" e de suas observações antropológicas sobre a sobrevivência de práticas coletivistas para uma estratégia política que situava nas comunidades indígenas o ponto de partida para uma via socialista própria aos países indo-americanos. (LOWY, 2005, p.22).

Entender o capitalismo como um fenômeno mundial é o mesmo que compreender a possibilidade socialista como tal, pois é direcionado à universalidade e não apenas ao mundo Ocidental, a proposta de Mariátegui não é fazer uma cópia do socialismo europeu, mas com base na análise concreta da realidade concreta e própria de seu país, criar um socialismo indo-americano qeu seja capaz de apreender o passado comunista agrário do país, ou seja, das sociedades incas. (LOWY, 2006, p.23).

A estratégia socialista de Mariátegui está diretamente relacionada com uma revolução agrária, ou seja, a expropriação das terras dos grandes latifundiários para os índios. A proposta significa uma recusa das teses deterministas e positivistas do Comintern, o que significa um revisionismo de novo tipo que luta para o combate dessas teses com a importância de compreender o capitalismo como algo mundial que possui diferenças mesmo quando observado sua totalidade: a acumulação de capital, a exploração do trabalho assalariado e a retirada de mais-valor.

As questões nacionais e raciais se relacionam com a questão revolucionária e com a autoemancipação das classes subalternas peruanas numa relação dialética entre os sindicatos e as comunidades indígenas, que é o elemento fundamental na auto-organização da classe trabalhadora para a construção do projeto socialista peruano. Para o autor, a práxis, a tática política e a linha dependem da corrente predominante; por isso, o mais certo é confiar nas massas que são quem vive o dia a dia, são quem enxergam a realidade, são os trabalhadores e a maioria.

Além disso, notamos algumas questões concretas que Mariátegui estabelece: a organização nacional da classe trabalhadora, a solidariedade das reivindicações indígenas, a questão de uma central única dos trabalhadores pautada em uma unidade proletária com a necessidade de contar com os meios de propaganda - o proletariado deve criar sua própria imprensa --, e a defesa das instituições da cultura popular e o desenvolvimento do trabalho.

Essas questões concretas, para uma proposta socialista, podem ser vistas como um programa classista que é capaz de superar o espírito corporativista do 
trabalho especializado e das categorias. "La vanguardia obrera tiene el deber de impulsionar y dirigir la organización del proletariado peruano, misión que reclama un sentido de responsabilidade (...)." (MARIÁTEGUI, 1974, p.118).

Portanto, é possível compreender que o desenvolvimento da consciência de classes está relacionado com a solidariedade e com todas as reivindicações fundamentais da classe trabalhadora, o que se compreende como disciplina revolucionária para um determinado fim, com o objetivo que o proletariado seja a vanguarda e que seja o criador de uma nova realidade, capaz de elaborar novos organismos com a finalidade de coordenação efetiva das relações das organizações dos trabalhadores.

\section{Considerações Finais}

É possível concluir este trabalho com a observação que a revolução na Rússia foi de grande importância para transformar as consciências de operários, camponeses e intelectuais do período determinado. A revolução socialista que se espalhou para inúmeros países do Leste Europeu, chegou ao Peru e teve outra receptividade e outras organizações, ainda que semelhantes com as táticas e estratégias comunistas. No cenário italiano, a revolução socialista foi derrotada no final de 1920 devido à ausência dos institutos do proletariado não apoiarem o movimento dos Conselhos de Fábrica, de maneira tal, que foi aberto espaço para o surgimento do fascismo (1919). No caso do Peru, não houve a formação de uma classe dirigente peruana, pois os grupos criados pela exportação de guano e salitre estavam ligados aos núcleos feudais e não às teorias revolucionárias ou ao desenvolvimento da consciência de classe.

É nesse sentido que a relação entre Gramsci, Mariátegui e Sorel se faz presente. Gramsci foi acusado muitas vezes pelo movimento socialista reformista de anarquista e idealista. Assim como intelectuais denominam o autor peruano de romântico. O que motivou, no entanto, este trabalho foi a matriz crítica marxista de Mariátegui e sua excelente capacidade de compreender as questões objetivas e subjetivas de seu país e da América Latina. Nesse sentido, Gramsci realiza algo semelhante ao compreender que a filosofia da práxis é capaz de modificar diversas fases culturais e sociais, enquanto, para Mariátegui, uma das funções do socialismo 
seria a de buscar na produtividade a criação de uma moral de produtores para o antagonismo ao capital. Esse é um ponto em consonância com os textos de Gramsci no período dos Conselhos de Fábricas. Para tanto, em ambos os autores é possível notar que o proletariado seria capaz de desenvolver-se como produtor por meio da fábrica e das relações transformadoras do trabalho e da consciência, além de realizarem críticas ao que diz respeito ao mito de Sorel, justamente por se tratar de um processo espontâneo das massas que pode ou não conter um elemento revolucionário e diretivo.

Portanto, a necessidade de compreender as formas organizacionais do movimento dos trabalhadores estaria/está relacionada em compreender também a história do movimento operário para a emancipação da classe trabalhadora, independente da cultura ou formação social. Ao compreender as condições objetivas e subjetivas do socialismo na América Latina, conclui-se que se tratou de uma ramificação dos movimentos sócio-políticos e culturais, mas com diferenças dos movimentos socialistas na Europa. A obra de Mariátegui possui justamente o diferencial a ser buscado: o de necessidade e importância das questões sociais, econômicas, políticas e culturais do Peru e da América Latina. Para tanto, a fim de compreender o pensamento político ideológico de Mariátegui foi de grande importância uma análise do processo de tradutibilidade que o autor realiza do processo revolucionário internacional e do desenvolvimento do capitalismo e suas implicações econômicas e sociais.

\section{Referências bibliográficas}

DEL ROIO, M. Lenin e a Internacional. In: Lenin: Teoria e Prática Revolucionária. (Org.) DEO, A. MAZZEO, A. DEL ROIO, M. São Paulo: Cultura Acadêmica 2015.

ESCORSIM, L. Mariátegui: vida e obra. São Paulo: Expressão Popular, 2006.

GRASMCI, A. In: COUTINHO, C. (Org.). Escritos Políticos (1910-1921). Rio de Janeiro: Civilização Brasileira, 2004.

LÖWY, Michael. Nem decalque, nem cópia: o marxismo romântico de José Carlos Mariátegui. In: MARIÁTEGUI, J. C. Por um socialismo indo-americano. Seleção e introdução de Michael Löwy. Rio de Janeiro: Editora da UFRJ, 2006.

MACHADO, Marília Gabriella Borges. A importância da cultura crítica na construção de um novo Estado. Revista de Ciências do Estado. Belo Horizonte: v. 5, n. 1, e13164. ISSN: 2525-8036 
MARIÁTEGUI, J. C. El alma matinal y otras estaciones del hombre de hoy. Lima: Biblioteca Amauta, 1970.

Ideología y política. Lima: Amauta, 1974.

Peruanicemos al Perú. Lima: Amauta, 1972.

Omega, 1975.

Sete ensaios de interpretação da realidade peruana. São Paulo: Alfa-

MELIS, Antonio. Mariátegui, el primer marxista de América. In: ARICÓ, J. (org.). Mariátegui y los orígenes del marxismo latinoamericano. México D.F.: Siglo XXI, 1978.

SOREL, Georges. Reflexões sobre a violência. São Paulo: Martins Fontes, 1992. 